\title{
Missense variants in the human peroxisome proliferator-activated receptor- $\gamma 2$ gene in lean and obese subjects
}

\author{
A Hamann, H Münzberg, P Buttron, B Büsing, A Hinney ${ }^{1}$, H Mayer ${ }^{2}$, W Siegfried ${ }^{3}$, J Hebebrand ${ }^{1}$ and H Greten \\ Medizinische Kernklinik und Poliklinik, Universitäts-Krankenhaus Eppendorf, Hamburg, Germany, ${ }^{1}$ Klinik für Psychiatrie und Psychotherapie des Kindes- \\ und Jugendalters, Philipps-Universität Marburg, Marburg, Germany, ${ }^{2}$ Klinik Hochried, Murnau, Germany and ${ }^{3}$ Adipositas-Rehabilitationszentrum \\ Insula, Berchtesgaden, Germany
}

(Correspondence should be addressed to A Hamann, Medizinische Kernklinik und Poliklinik, Universitäts-Krankenhaus Eppendorf, Martinistraße 52, 20246 Hamburg, Germany)

\begin{abstract}
The peroxisome proliferator-activated receptor- $\gamma 2(\operatorname{PPAR} \gamma 2)$ is almost uniquely expressed in adipose tissue and is of major importance for fat cell differentiation and lipid metabolism. This study was undertaken to assess whether two missense variants in the PPAR $\gamma 2$ gene are associated with earlyonset obesity. A previously described polymorphism encoding for an amino acid exchange in codon 12 (Pro12Ala) was detected with allele frequencies of 0.13 in 296 markedly obese children and adolescents and 0.14 in 130 lean individuals. A Pro115Gln variant, which had been linked to obesity in Germans in a previous association study, was not detected in any of our obese or lean subjects, who are also of German origin. We conclude from our data that these two variants in the PPAR $\gamma 2$ gene are unlikely to contribute to the high prevalence of early-onset obesity.
\end{abstract}

European Journal of Endocrinology 141 90-92

\section{Introduction}

Overweight and obesity affect almost half of the population in many industrialized countries. The association with type 2 diabetes, dyslipidemia and hypertension creates increased morbidity and mortality risks for obese individuals. Obesity is viewed as a multifactorial disorder, with genetic factors playing an important pathogenic role.

Products of relevant genes may be involved in the regulation of food intake, energy expenditure or nutrient partitioning. The sum of presumably several genetic effects and their interaction with environmental and behavioral conditions, such as increased caloric and fat intake or decreased physical activity, can result in energy imbalance and increased fat mass.

In recent years, the discovery of leptin and other molecules secreted by fat cells has markedly changed our view of adipose tissue being a rather passive triglyceride store (1). Furthermore, the peroxisome proliferatoractivated receptor- $\gamma 2$ (PPAR $\gamma 2)$ was cloned and identified as a central regulator of fat cell differentiation (2, reviewed in 3,4). PPAR $\gamma$ is a transcription factor that belongs to the family of nuclear receptors. Two isoforms, PPAR $\gamma 1$ and PPAR $\gamma 2$, are formed by alternative promoters and splicing. In contrast to the widespread expression of $\operatorname{PPAR} \gamma 1, \operatorname{PPAR} \gamma 2$ is almost selectively expressed in adipose tissue. Overexpression of PPAR $\gamma 2$ in fibroblast cell lines causes lipid accumulation and differentiation into mature adipocytes (5). PPAR $\gamma 2$ mRNA is regulated by several nutritional and hormonal factors in both rodents and humans $(6,7)$. Endogenous ligands for PPAR $\gamma$ include fatty acids and some prostaglandins, while even more attention has been attracted by the identification of the thiazolidinedione family of insulin sensitizers as acting via PPAR $\gamma$.

Because it is an attractive candidate gene for the dysregulation of energy balance, single strand conformational polymorphism-based screening was applied and two missense variants in the PPAR $\gamma 2$ coding sequence were identified $(8-10)$. In the unique first exon, a CG base exchange results in a proline to alanine amino acid substitution in codon 12, while a GT base exchange in the second exon shared by both PPAR $\gamma$ isoforms introduces a substitution of proline to glutamine in codon 115. Somewhat conflicting data have recently been published as to whether Pro12Ala is associated with obesity (11) or with a lower body mass index (BMI) (12). In the latter study, a decreased binding affinity of the mutated variant to its promoter response element and a decreased activation of transcription have been demonstrated in various cell lines (12). Pro115Gln has 
recently been found in 4 of 121 severely obese individuals (10). Interestingly, the altered protein causes accelerated adipocyte differentiation and may be directly involved in increased triglyceride accumulation.

Given the above data and the importance of PPAR $\gamma 2$ for the regulation of energy storage, this study was undertaken to determine whether missense variants in the PPAR $\gamma 2$ gene are associated with early-onset human obesity in a German population.

\section{Subjects and methods}

A group of 296 extremely obese children and adolescents was recruited at the Children's Hospital Hochried and the Obesity Treatment Centre Insula, which both specialize in the inpatient treatment of extremely obese young individuals. Ninety-seven percent of the obese subjects had a BMI above the 95th percentile, 61\% exceeded the 100th BMI percentile. The second study group of 130 underweight students was selected at the University of Marburg. They were characterized by a BMI below the 13th percentile, absence of somatic disorders and consumption of less than ten cigarettes per day. Probands with anorexia nervosa were excluded from the present sample of underweight individuals that represents an extension of a study group described previously (13), and both groups have been characterized in detail before (14).

Genetic studies were approved by the ethics committees of the Universities of Marburg and Hamburg. Written informed consent was obtained from all participants or, in case of minors, their parents.

EDTA anticoagulated venous blood samples were collected from the aforementioned individuals and leukocyte DNA was isolated as described (13). For restriction fragment length polymorphism (RFLP)-based genotyping, a $306 \mathrm{bp}$ fragment including exon 1 of the human PPAR $\gamma 2$ gene and containing the Pro12Ala variant was amplified by PCR using oligonucleotides 5'-GCCAATTCAAGCCCAGTC-3' and 5'-CGTCCCCAATAGCCGTATC-3'. A 118 bp fragment containing the Pro115Gln variant was amplified using primers $5^{\prime}$ AATCAAAGTGGAGCCTGCATGT-3' and 5'-ATCTCCACAGACACGACATT-3'. Seventy-five nanograms genomic DNA were added to $20 \mu \mathrm{l}$ of reaction mixture (14) and amplification over 35 cycles was carried out in an automated thermal cycler at $94^{\circ} \mathrm{C}$ for $1 \mathrm{~min}, 55^{\circ} \mathrm{C}$ (Pro12Ala) or $50^{\circ} \mathrm{C}$ (Pro115Gln) for $1 \mathrm{~min}$ and $72^{\circ} \mathrm{C}$ for $2 \mathrm{~min}$. Ten microliters PCR product were digested with HgaI (Pro12Ala) or HincII (Pro115Gln) and subjected to $3 \%$ agarose electrophoresis or $10 \%$ PAGE with ethidium bromide.

\section{Results}

The base exchange predicting the Pro12Ala variant introduces an Hgal site in the amplified sequence,

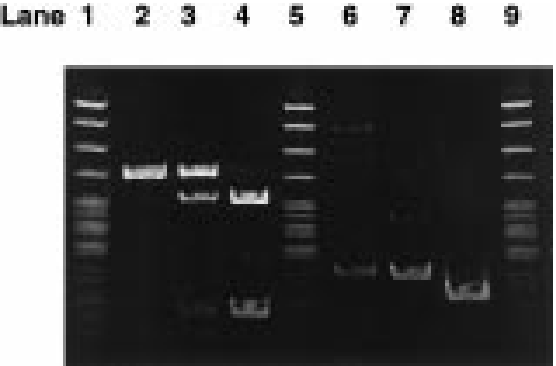

Figure 1 PCR-RFLP detection of PPAR 2 missense variants by $P A G E$, ethidium bromide staining and UV transillumination. Lanes 1, 5 and 9: pBR322 DNA-Mspl marker. Lane 2: wildtype for codon 12 variant. Lane 3: heterozygous for codon 12 variant. Lane 4: homozygous for codon 12 missense mutation. Lane 6: wildtype for codon 115 variant (amplified from human genomic DNA). Lane 7: wildtype for codon 115 variant (amplified from a plasmid containing codon 115 wildtype DNA). Lane 8: codon 115 mutated variant (amplified from a plasmid containing codon 115 missense mutation; 22 bp fragment not visualized).

resulting in fragments of 220 and 86 bp for the mutated allele (Fig. 1).

RFLP analysis revealed an allele frequency of 0.13 for the Pro12Ala variant in 296 obese children and adolescents. Two hundred and twenty (74.3\%) were homozygous for the wildtype allele, while seventy three $(24.7 \%)$ were heterozygous and three $(1.0 \%)$ were homozygous for the mutated allele.

In the lean group, 95 of 130 individuals (73.1\%) were homozygous for the wildtype allele, while 35 $(26.9 \%)$ were heterozygous for the variant with no homozygotes. Therefore, the frequency of the mutated allele in the lean group $(0.14)$ was not different from the obese $\left(P=0.98\right.$ by $\chi^{2}$-test). The Pro115Gln variant that should have created an additional HincII site with fragments of 22 and $96 \mathrm{bp}$, in contrast to the $118 \mathrm{bp}$ wildtype band, was found neither in 296 obese nor in 130 lean individuals.

A DNA fragment including the mutant variant provided by Dr M Ristow (Joslin Diabetes Centre, Boston, MA, USA) was used as a positive control to ensure the correct cut by the restriction enzyme HincII.

\section{Discussion}

The importance of PPAR $\gamma 2$ in lipid, glucose and energy metabolism is well established. Since PPAR $\gamma 2$ promotes adipocyte differentiation, it is an attractive candidate gene for states of altered triglyceride storage, such as obesity or conditions associated with underweight. Variants in the PPAR $\gamma 2$ gene could possibly lead to both a decreased or accelerated adipocyte differentiation and lipid accumulation. In a recent study, a variant in codon 115 was demonstrated to be an example of the latter (10). When a mutated PPAR $\gamma 2$ allele previously found in 4 of 121 obese German individuals was overexpressed in murine fibroblasts, it led to a markedly more pronounced adipocyte differentiation than wildtype 
$\operatorname{PPAR} \gamma 2$. This is presumably due to the fact that the mutation is next to a serine phosphorylation site in codon 114, which has been shown to be of major importance for the negative regulation of PPAR $\gamma 2$ gene expression (15).

It appeared tempting to speculate that this variant could be associated with early-onset human obesity. However, our RFLP analysis revealed that not a single individual within a large group of morbidly obese children and adolescents or lean individuals carried an allele with the mutation in codon 115. Because both of our study groups are of German origin, it appears that the reported variant (10) is rare in the German population. Thus, it seems unlikely that the Pro115Gln variant explains a relevant proportion of obesity in this population. Furthermore, a previously identified variant in codon 12 was associated neither with obesity nor with leanness.

Although we cannot fully exclude the possibility that an association may be found in other populations, our data make it rather unlikely that variants in the PPAR $\gamma 2$ gene contribute to the high prevalence of human obesity.

\section{Acknowledgements}

We thank Dr M Ristow (Joslin Diabetes Centre, Boston, MA, USA) for a positive control sample of the Pro115Gln variant and thank all participants for their cooperation. This work was supported by the Deutsche Forschungsgemeinschaft (DFG Ha 2093/2-2, Graduiertenkolleg 336 and Klinische Forschergruppe Re 471/11-1).

\section{References}

1 Spiegelman BM \& Flier JS. Adipogenesis and obesity: rounding out the big picture. Cell 199687 377-389.

2 Tontonoz P, Hu E, Graves RA, Budavari AI \& Spiegelman BM. mPPAR gamma 2: tissue-specific regulator of an adipocyte enhancer. Genes and Development 19948 1224-1234.

3 Auwerx J, Martin G, Guerre-Millo M \& Staels B. Transcription, adipocyte differentiation, and obesity. Journal of Molecular Medicine 199674 347-352.

4 Spiegelman BM. PPAR-gamma: adipogenic regulator and thiazolidinedione receptor. Diabetes 199847 507-514.
5 Tontonoz P, Hu E \& Spiegelman BM. Stimulation of adipogenesis in fibroblasts by PPAR gamma 2, a lipid-activated transcription factor. Cell 199479 1147-1156.

6 Vidal-Puig A, Jimenez-Linan M, Lowell BB, Hamann A, Hu E, Spiegelman B et al. Regulation of PPAR gamma gene expression by nutrition and obesity in rodents. Journal of Clinical Investigation $1996972553-2561$.

7 Vidal-Puig AJ, Considine RV, Jimenez-Linan M, Werman A, Pories WJ, Caro JF et al. Peroxisome proliferator-activated receptor gene expression in human tissues. Effects of obesity, weight loss, and regulation by insulin and glucocorticoids. Journal of Clinical Investigation 199799 2416-2422.

8 Yen CJ, Beamer BA, Negri C, Silver K, Brown KA, Yarnall DP et al. Molecular scanning of the human peroxisome proliferator activated receptor gamma (hPPAR gamma) gene in diabetic Caucasians: identification of a Pro12Ala PPAR gamma 2 missense mutation. Biochemical and Biophysical Research Communications $1997241270-274$.

9 Vigouroux C, Fajas L, Khallouf E, Meier M, Gyapay G, Lascols O et al. Human peroxisome proliferator-activated receptor-gamma 2: genetic mapping, identification of a variant in the coding sequence, and exclusion as the gene responsible for lipoatrophic diabetes. Diabetes 199847 490-492.

10 Ristow M, Müller-Wieland D, Pfeiffer A, Krone W \& Kahn CR. Obesity associated with a mutation in a genetic regulator of adipocyte differentiation. New England Journal of Medicine 1998 339 953-959.

11 Beamer BA, Yen CJ, Andersen RE, Muller D, Elahi D, Cheskin LJ et al. Association of the Pro12Ala variant in the peroxisome proliferator-activated receptor-gamma 2 gene with obesity in two Caucasian populations. Diabetes 199847 1806-1808.

12 Deeb SS, Fajas L, Nemoto M, Pihlajamaki J, Mykkanen L, Kuusisto $\mathrm{J}$ et al. A Pro12Ala substitution in PPARgamma2 associated with decreased receptor activity, lower body mass index and improved insulin sensitivity. Nature Genetics 199820 284-287.

13 Hinney A, Barth N, Ziegler A, von Prittwitz S, Hamann A, Hennighausen $\mathrm{K}$ et al. Serotonin transporter gene-linked polymorphic region: allele distributions in relationship to body weight and in anorexia nervosa. Life Sciences 199761 L295L303.

14 Hamann A, Tafel J, Büsing B, Münzberg H, Hinney A, Mayer H et al. Analysis of the uncoupling protein-1 (UCP1) gene in obese and lean subjects: identification of four amino acid variants. International Journal of Obesity and Related Metabolic Disorders 199822 939-941.

$15 \mathrm{Hu}$ E, Kim JB, Sarraf P \& Spiegelman BM. Inhibition of adipogenesis through MAP kinase-mediated phosphorylation of PPARgamma. Science 1996274 2100-2103.

Received 30 November 1998

Accepted 4 March 1999 